\title{
Large medical equipment in hospital management and its economic benefits
}

\author{
Maojun Wang
}

\author{
Received: July 15, 2020. Revised: September 17, 2020. Accepted: September 25, 2020. \\ Published: September 28, 2020.
}

\begin{abstract}
Large medical equipment management is one of the important parts in the management of hospital, which has great meaning to the hospital development. However, the current use of medical equipment generally has the problem of high cost and low efficiency, which brings great difficulty to hospital management. Based on the statistics of investment cost, operation cost and medical equipment income of some large medical equipment in a hospital in Suzhou in recent three years, the economic benefits of large medical equipment were analyzed in aspects of payback period and method of rate of return on investment. The results demonstrated that the investment cost and operation cost of the large medical equipment in the hospital management were both high, and the economic benefits were significantly different between different equipment. Then based on this, some Suggestions were put forward for equipment management, and the role of economic benefit analysis in hospital management was illustrated to provide some theoretical reference for further research.
\end{abstract}

Keywords - Cost analysis, economic benefits, hospital management, medical equipment.

\section{INTRODUCTION}

$\mathrm{W}$ ITH the rapid development of science and technology capability and economic capability of China, the popularizing rate of large medical equipment in various hospitals in different hospital also become higher and higher. According to statistics, the number of Doppler B ultrasound has exceeded 6,000 in China, with an annual increase of 600. The management of large medical equipment is an important work [1], which has been extensively focused [2]. From the current situation, there are still many phenomena of resource waste [3]. Reasonable management can avoid the repeated purchase of medical equipment as far as possible, so as to reduce the purchase cost and increase the economic benefits of the hospital $[4,5]$. Through the cost-benefit analysis of medical equipment, we can have a better understanding of the use of equipment [6], and then take it as the best basis for equipment management [7]. More and more experts in the academic world tend to study the economic benefits of large medical equipment and expect to reduce investment cost, increase hospital income and scientifically manage equipment through analysis of the

M. J. Wang is with the Medical Department, The First Affiliated Hospital of Soochow University, Suzhou, Jiangsu 215006, China (e-mail: wangmaojun@suda.edu.cn). economic benefits. Focusing on the increased large medical equipment in hospitals, Liu et al. [8] considered that analysis on the benefits of large medical equipment could promote the reasonable allocation and high-efficient use of medical equipment. Through analyzing the economic benefits of the wards of the radiology department of 15 comprehensive hospitals affiliated to Kerman Medical University, Jahad et al. [9] found that $80 \%$ of the wards of the radiology department had low economic efficiency and advised the managers to consider medical equipment with high cost benefits. Through collecting data from the comprehensive hospitals affiliated to Shiraz University of Medical Sciences and all the radiological units of those hospitals. Keshtkaran et al. [10] found that $75 \%$ of the radiation departments had poor economic benefits and recommend relevant departments to consider allocating optimal resources according to the price and investment cost of equipment in radiology department.

In this study, large medical equipment and its current management status was briefly introduced, then carry out economic benefit analysis, and according to the results of scientific management of medical equipment to put forward some suggestions, making some contributions to promote the development of hospitals.

\section{LARGE MEDICAL EQUIPMENT AND ECONOMIC BENEFITS}

\section{A. Large Medical Equipment}

Medical equipment refers to the modern equipment that must be used in the diagnosis and treatment in hospitals. Large medical equipment refers to medical equipment with high market value and volume and is usually expensive. Moreover, large medical equipment costs patients much and need large costs in maintenance and management. For example, cost of liquid helium, cooling liquid, technical support, software and other auxiliary accessories is needed in the maintenance of equipment. Large medical equipment is the embodiment of hospital scientific research level and technical level.

According to the purchasing price, large medical equipment can be divided into two types:

(1) type A: equipment more than 30 million yuan, such as TOMO (Fig. 1), linear accelerator (Fig. 2), X-ray stereotactic radiotherapy system (Fig. 3), etc.;

(2) type B: equipment less than 30 million yuan, such as tomoscanner (Fig. 4), surgical robot (Fig. 5), Gamma-ray 
INTERNATIONAL JOURNAL OF CIRCUITS, SYSTEMS AND SIGNAL PROCESSING

stereotactic radiotherapy system (Fig. 6), magnetic resonance imaging (MRI) system (Fig. 7), etc.

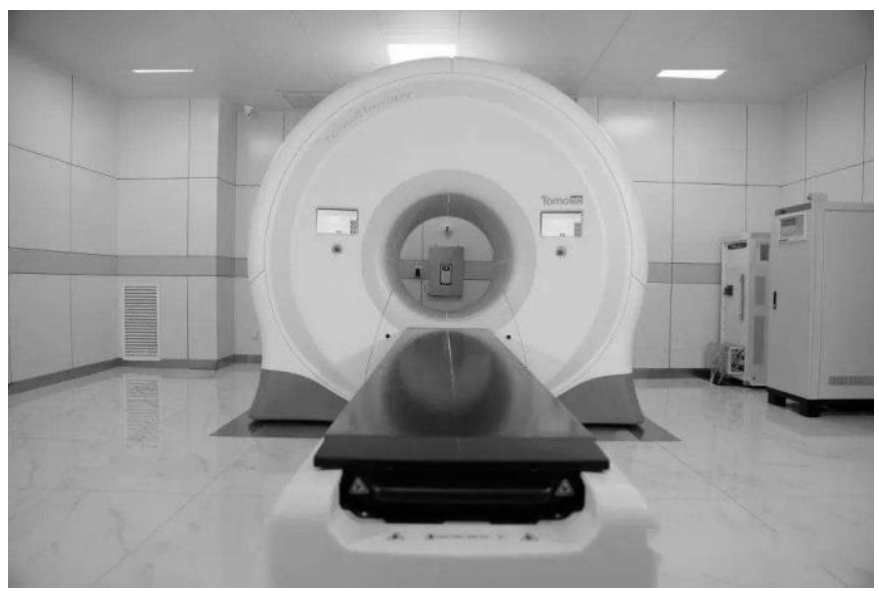

Fig. 1 TOMO

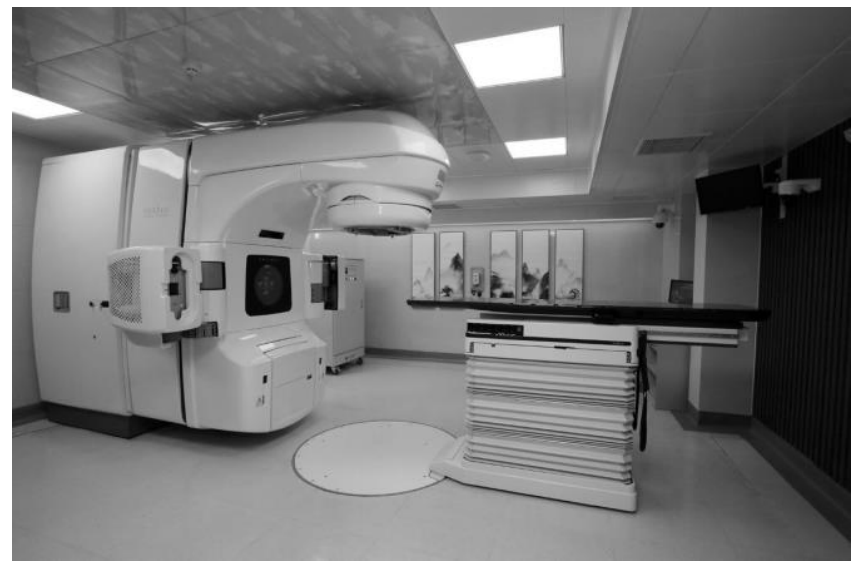

Fig. 2 Linear accelerator

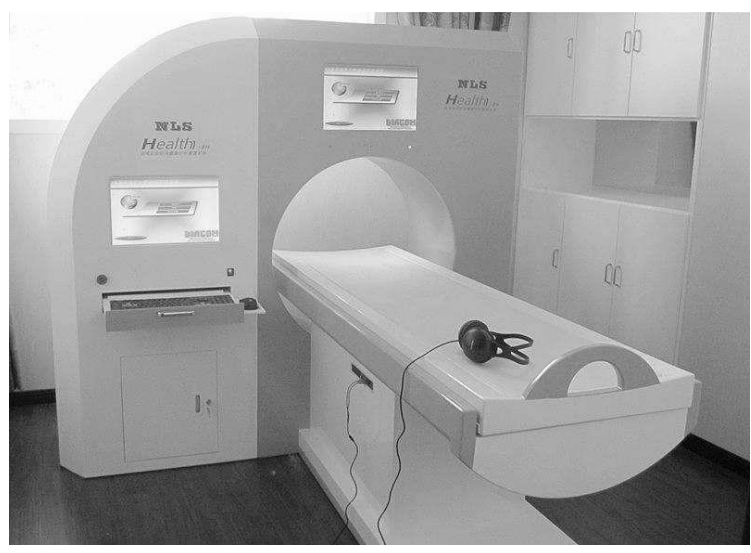

Fig. 4 Tomoscanner

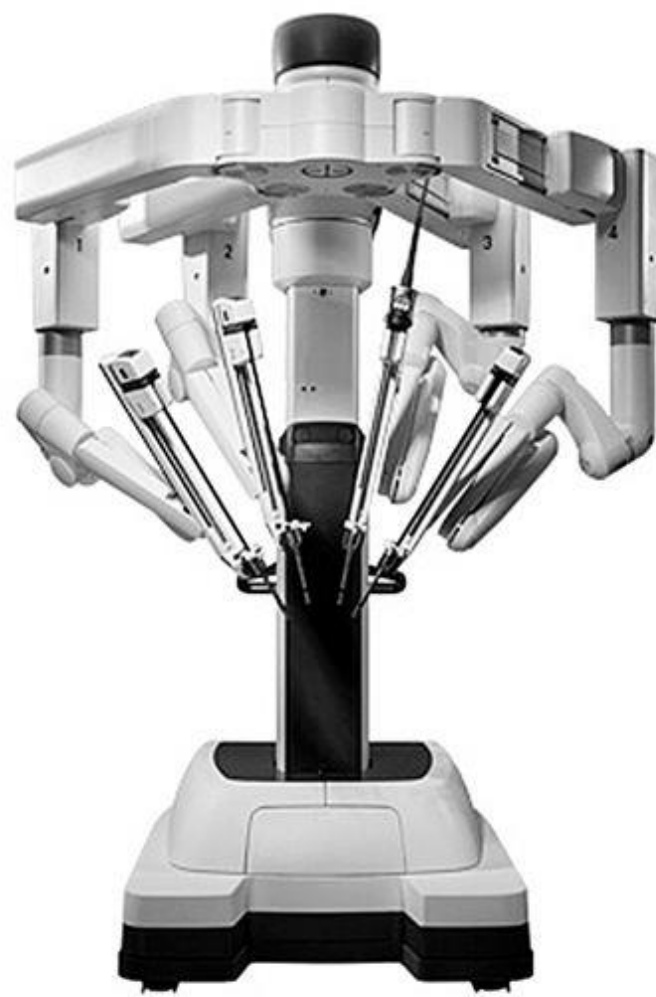

Fig. 5 Surgical robot

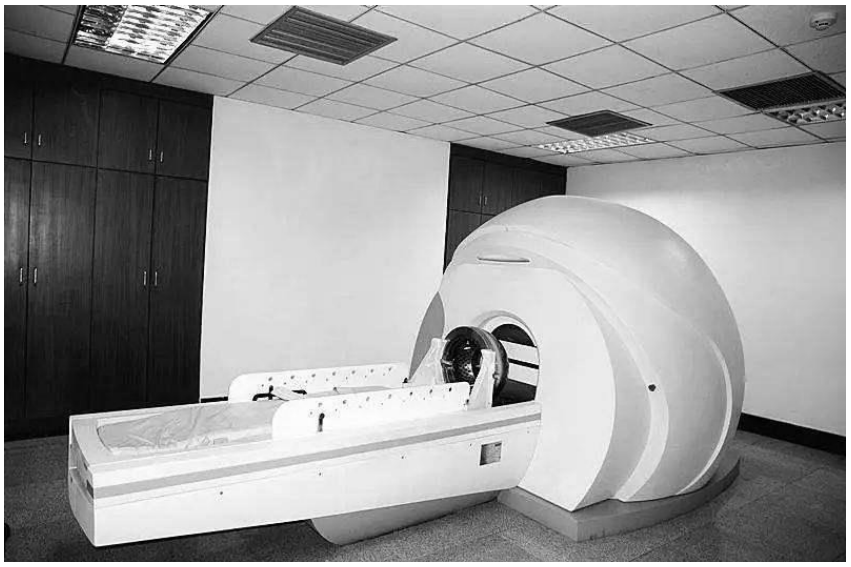

Fig. 6 Gamma-ray stereotactic radiotherapy system 


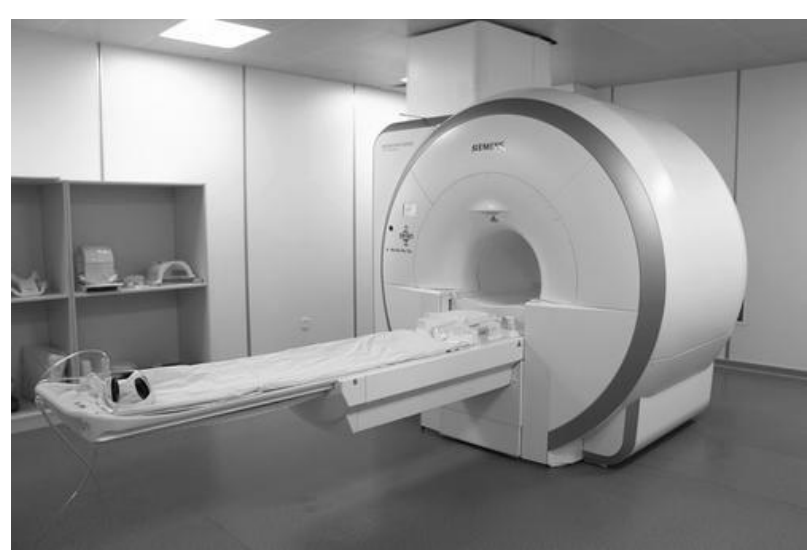

Fig. 7 Magnetic resonance imaging system

According to the purpose, large medical equipment can be divided into three types:

(1) diagnostic equipment: equipment for doctors to understand the state of patients through diagnosis such as $\mathrm{X}$ ray and electrocardiography;

(2) treatment equipment: equipment for therapeutic use, such as chemotherapy equipment and nursing equipment;

(3) auxiliary equipment: equipment with auxiliary function for diagnosis and treatment, such as image acquisition equipment and blood processing equipment.

\section{B. Equipment Management}

The management if equipment mainly includes:

(1) purchasing management: the name, price, and term of service of equipment should be clear in the process of purchasing;

(2) warehouse management: the warehouse should formulate systems, such as registration, application, and returning and make classification management after the equipment enter the warehouse;

(3) maintenance management: when the equipment needs maintenance, maintenance personnel should perform their duties and give treatment scheme;

(4) retirement management: when the equipment exceeds its service life, the equipment should be scraped compulsively, and moreover, the reusable parts are recycled;

(5) document management: professional staffs are needed to sort and file relevant information of the equipment and establish perfect files.

\section{The Existing Problems}

Large medical equipment can not only improve the level and quality of medical treatment [11], but also bring huge benefits. Moreover, the constant updating of equipment also stimulates hospitals' pursuit of high-tech equipment. However, at present, more and more hospitals have equipment idle phenomenon, not to achieve high economic benefits.

At present, there are still many problems in equipment management.

(1) The efficiency of equipment is too high or too low. In the same area, the higher the number of the same large medical equipment is, the lower the efficiency will be. If the population of the same region has a fixed demand for medical equipment, but the number of medical equipment far exceeds the demand, then the efficiency of most devices will be reduced. Some of the smaller facilities, despite the purchase of large medical equipment, are extremely inefficient and rarely used. However, in large hospitals, the workload of computed tomography (CT) and MRI is large, which is not conducive to the sustainable development of equipment. Currently, the medical resource allocation in China is not even [12], and they mainly concentrate in Beijing, Shanghai, etc. Moreover, the configuration in cities is superior to that in towns, which leads to the phenomenon that people are tended to go to hospitals in large cities; as a result, the medical equipment in towns is idled.

(2) The amount of equipment is increasing, but the total amount is still not enough. Although the configuration of equipment in China is increasing every year, there is a large gap with the developed countries.

(3) Specific medical equipment management measures are not perfect [13], professional management personnel is not enough, or the level of management personnel is low; therefore, the equipment cannot be effectively managed and maintained. The wrong evaluation on the use of equipment before purchasing leads to low use efficiency.

\section{Significance of Economic Benefit Analysis}

Economic benefit analysis, a method of economic decision-making, achieves the economic evaluation of the target through the evaluation of financial data. At present, the charging standards of various items in the hospital are based on the comprehensive data reported by primary hospitals. The analysis of the economic benefits of equipment can provide a reliable basis for the relevant national departments to formulate medical prices, which is conducive to the development of medical reform and the healthy development of hospital investment.

For the hospital management, the analysis of the economic benefits of equipment can provide a reference for the next time of purchase of equipment, help the decision maker make appropriate decisions, and provide a scientific guidance for the investment in medical equipment.

For departments that need to use these equipment, the economic benefit analysis can help them better understand the use and maintenance of different equipment and master the requirements of departments for equipment and the level of management, thereby strengthening equipment management and saving department expenses.

\section{The ANALYSIS METHOD OF ECONOMIC BENEFITS}

\section{A. Overview of Cost of Large Medical Equipment}

The cost of large medical equipment is generally composed of two parts, as shown in Fig. 8. 


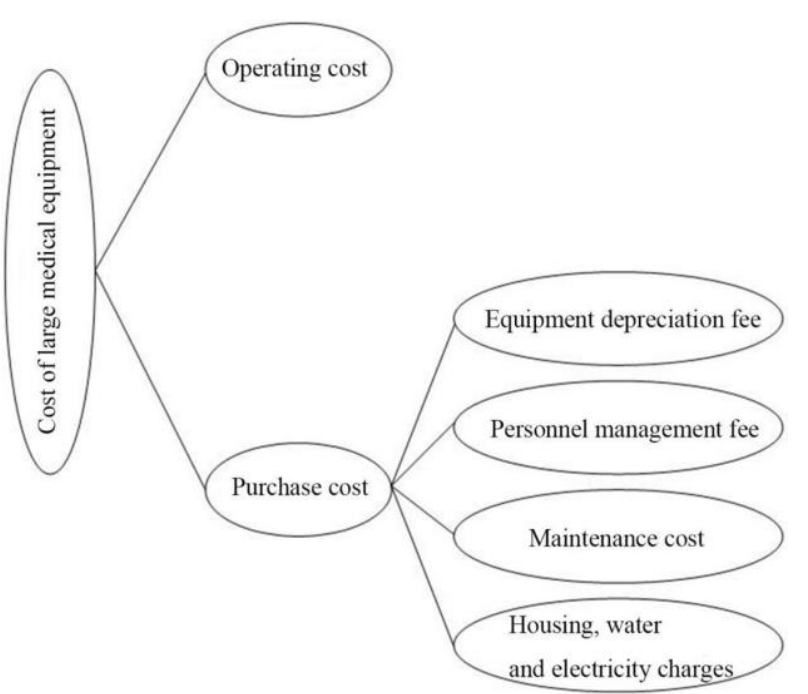

Fig. 8 Cost composition of large medical equipment

The purchase cost refers to the price of equipment purchased. The operation cost is generally composed of four parts.

(1) Depreciation refers to the decrease of asset value. Equipment depreciation cost refers to the currency estimate of value consumed.

(2) Personnel and management cost includes salary and bonus of staffs in relevant departments and the expense of equipment utilization and management.

(3) Maintenance and repairing cost includes the maintenance and repairing cost of equipment and cost of consumed materials.

(4) Cost of building, water and electricity includes charge for use of building, maintenance cost of building and cost of water, electricity, and gas.

\section{B. The Analysis Method of Economic Benefits}

(1) Rate of return on investment [14] refers to the ratio of total annual net return to gross investment. Its calculation formula is:

Rate of return on investment $=$ (annual net return/gross investment) * $100 \%$.

(2) Payback period [15] refers to the period for recovering cost according to the income, depreciation cost and maintenance cost of medical equipment under normal operation. Its calculation formula is:

Payback period $($ year $)=$ gross investment/annual net return .

A short payback period means that the hospital can recoup the investment on equipment in a short period, i.e., the economic benefit of equipment is good (Table 1).

Table 1 Payback period and the corresponding economic benefit

\begin{tabular}{|l|l|}
\hline Payback period $\mathrm{x}$ (year) & Economic benefits \\
\hline $\mathrm{X} \leq 2$ & Excellent \\
\hline $2<\mathrm{X} \leq 4$ & Good \\
\hline $4<\mathrm{X} \leq 6$ & General \\
\hline $\mathrm{X} \geq 6$ & Poor \\
\hline
\end{tabular}

\section{INSTANCE ANALYSIS}

Taking a hospital in Suzhou as an example, the equipment configuration in the hospital is shown in Table 2.

Table 2 The configuration of large medical equipment

\begin{tabular}{|l|l|l|l|}
\hline Equipment & Amount/n & $\begin{array}{l}\text { Unit } \\
\text { price/ ten } \\
\text { thousand } \\
\text { yaun }\end{array}$ & $\begin{array}{l}\text { Number of } \\
\text { operators on } \\
\text { every } \\
\text { equipment/n }\end{array}$ \\
\hline CT & 3 & 1120 & 5 \\
\hline DR machine & 3 & 260 & 3 \\
\hline $\begin{array}{l}\text { Power frequency } \\
\text { X-ray machine }\end{array}$ & 3 & 108 & 3 \\
\hline $\begin{array}{l}\text { Hyperbaric } \\
\text { oxygen chamber }\end{array}$ & 1 & 82 & 3 \\
\hline $\begin{array}{l}\text { B ultrasound } \\
\text { machine }\end{array}$ & 13 & 320 & 1 \\
\hline $\begin{array}{l}\text { Extracorporeal } \\
\text { shock wave } \\
\text { lithotripter }\end{array}$ & 1 & 45 & 3 \\
\hline $\begin{array}{l}\text { Digital subtraction } \\
\text { angiography X-ray } \\
\text { machine }\end{array}$ & 2 & 600 & 3 \\
\hline MRI machine & 2 & 1300 & 6 \\
\hline
\end{tabular}

It was seen from Table 2 that the amount of B ultrasound machines in the hospital was the largest, and the number of the other equipment was smaller than 5; the number of operators needed by a B ultrasound machine was the smallest, and the number of operators needed by a MRI machine was the largest.

The income and expenditure in the using process of those equipment are shown in Fig. 9.

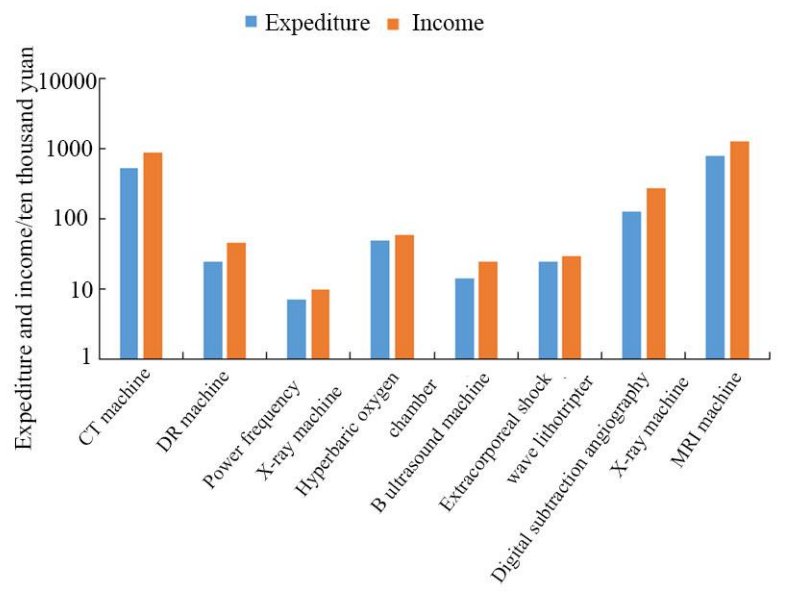

Fig. 9 The income and expenditure of equipment

It was seen from Fig. 9 that the income of the equipment was higher than the expenditure; the income and expenditure of CT and MRI machines were high, close to 10 million yuan, followed by digital subtraction angiography X-ray machine, which was about one million yuan; the income and expenditure of the other equipment were less than one million yuan, and the power frequency X-ray machine was the least, about 100,000 yuan. The annual net income of these equipment was calculated, 
as shown in Table 3.

Table 3 The annual net income of equipment/ten thousand yuan

\begin{tabular}{|l|l|}
\hline & Annual net income \\
\hline CT machine & 360 \\
\hline DR machine & 20 \\
\hline Power frequency X-ray machine & 3 \\
\hline Hyperbaric oxygen chamber & 10 \\
\hline B ultrasound machine & 11 \\
\hline $\begin{array}{l}\text { Extracorporeal shock wave } \\
\text { lithotripter }\end{array}$ & 5 \\
\hline $\begin{array}{l}\text { Digital subtraction angiography } \\
\text { X-ray machine }\end{array}$ & 145 \\
\hline MRI machine & 470 \\
\hline
\end{tabular}

It was seen from Table 3 that the annual net income of the MRI machine was the highest, reaching 4.7 million yuan, followed by CT machine, reaching 3.6 million yuan; the annual net income of the power frequency X-ray machine and extracorporeal shock wave lithotriptor was the lowest, which was 30,000 yuan and 50,000 yuan respectively.

According to the formula mentioned before, the economic benefit of the equipment was calculated, as shown in Fig. 10.

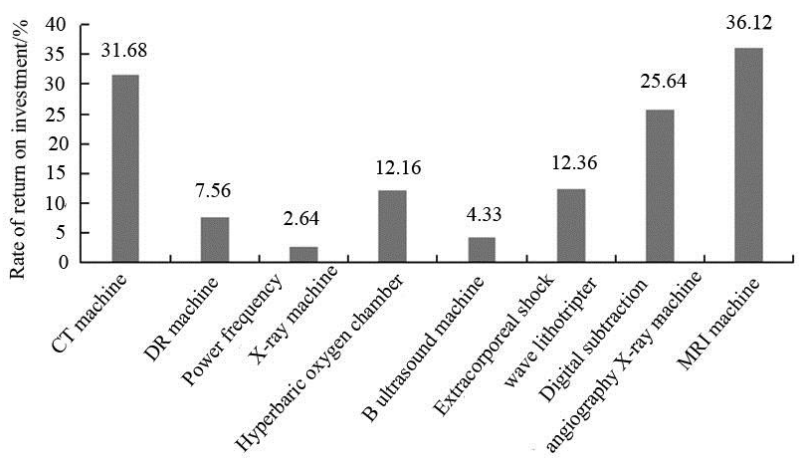

Fig. 10 Rate of return on investment

It was seen from Fig. 10 that the rate of return on investment of the MRI machine was the highest, reaching $36.12 \%$, followed by the CT machine, which reached $31.68 \%$. Among these equipment, the rate of return on investment of three equipment was below $10 \%$, which were the DR machine, power frequency $\mathrm{X}$-ray machine, and B ultrasound machine respectively, and the rate of return on investment of the power frequency X-ray machine is the lowest, only $2.64 \%$.

The payback period of the equipment is shown in Fig. 11.

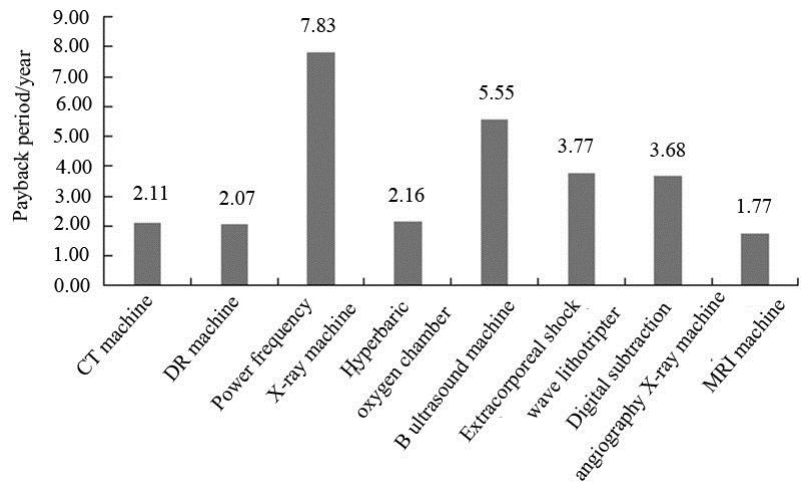

Fig. 11 Payback period

It was seen from Fig. 11 that the investment payback period of the equipment except the power frequency X-ray machine and $\mathrm{B}$ ultrasound machine was relatively short, the payback period of the MRI machine was the shortest, followed by $\mathrm{Dr}$ (2.07 years), CT and hyperbaric oxygen chamber (HBO) of 2.11 years and 2.07 years respectively. According to table 1, the equipment with good economic benefits in this hospital is nuclear magnetic resonance, and the better ones are CT, DR, hyperbaric oxygen chamber and extracorporeal shock wave lithotripter and digital subtraction angiography X-ray machine, the general B ultrasound machine, the difference is the power frequency X-ray machine.

The average diagnosis and treatment times and positive detection rate of each equipment are shown in Table 4.

Table 4 The use of equipment

\begin{tabular}{|l|l|l|}
\hline & $\begin{array}{l}\text { Average number of } \\
\text { patients being } \\
\text { diagnosed and } \\
\text { treated/ten thousand } \\
\text { people }\end{array}$ & Positive rate/\% \\
\hline CT machine & 1.12 & 85.16 \\
\hline DR machine & 0.22 & 84.62 \\
\hline $\begin{array}{l}\text { Power frequency X-ray } \\
\text { machine }\end{array}$ & 0.14 & 81.67 \\
\hline $\begin{array}{l}\text { Hyperbaric oxygen } \\
\text { chamber }\end{array}$ & 0.18 & $/$ \\
\hline B ultrasound machine & 0.07 & 84.56 \\
\hline $\begin{array}{l}\text { Extracorporeal shock } \\
\text { wave lithotripter }\end{array}$ & 0.01 & 87.12 \\
\hline $\begin{array}{l}\text { Digital subtraction } \\
\text { angiography X-ray } \\
\text { machine }\end{array}$ & 0.22 & 88.64 \\
\hline MRI machine & 1.23 & 91.33 \\
\hline
\end{tabular}

It was seen from Table 4 that only CT and MRI machines were used for more than 10,000 times, while the other equipment was used for less than 10,000 times. It showed that CT and MRI machines were efficient; therefore, their economic benefits were also good. The average number of patients diagnosed and treated by the extracorporeal shock wave lithotripter was the least, which was only 0.01 million, indicating that it was used seldom in the hospital. Figs. 7 and 8 
suggested that the power frequency X-ray machine with the worst economic benefit were used for diagnosis and treatment for 1,400 times, indicating that it had a large demand in the hospital. The positive rate of all the equipment was above $80 \%$, and the positive rate of the MRI machine was the highest, reaching $91.33 \%$, indicating that these equipment had good service efficiency.

\section{DISCUSSION}

Through the analysis of the economic benefits of large medical equipment, the use of equipment could be learned, so as to make reasonable guidance for the purchase and management of equipment. Therefore, managers should follow the principle of economy and rationality when introducing it [16].

Taking a hospital in Suzhou as an example, this study analyzed the configuration of the large-scale medical equipment and calculated the economic benefits. It was found from the results that most of the equipment in the hospital had good economic benefits. Among these equipment, B ultrasound machine had the largest number. In hospitals, B ultrasound machine has been widely used in the diagnosis of internal organs and internal tissues, which is noninvasive and dynamic. Its working principle is based on the ultrasonic wave. It can transform the signal into the graph for displaying, so as to realize the internal examination and diagnosis of the human body. It has high reliability, safety, and reliability; therefore, it has a large amount of use in the hospital. But the charge for B ultrasound machine is low, leading to low annual net income. The number of operators needed by CT and MRI machines was the largest, which indicated that the two equipment had high requirements for operators and the hospital attached great importance to them. In addition, CT and MRI machines have very important values in medical examination, and the examination cost is also relatively high, which brings high income for hospitals. The equipment with poor economic benefit has high cost of purchase and maintenance and is seldom used in hospital; however, these equipment are indispensable. For example, power frequency X-ray machine with the worst economic benefit plays an important role in medical diagnosis and treatment. Generally speaking, the economic benefits of large-scale equipment in the hospital are good. In the future equipment purchase and management, the number of CT and MRI machines can be appropriately increased to improve the economic benefits.

Through analysis, it was found that the hospital had the following problems.

(1) Lacking planning

When purchasing large-scale medical equipment, the departments lacked planning and usually applied for purchasing for temporarily.

(2) Complex purchasing process

Before purchasing large-scale medical equipment, the approval and signature of many departments were needed, which led to low efficiency.

(3) Lacking professional management staffs
Most of the equipment management staffs in the hospital did not receive professional training and learning.

(4) Delayed examination and maintenance for equipment

For the equipment in the hospital, most of the departments repaired the equipment only when there was a problems. The daily maintenance was lack of. Some expensive equipment was examined repeatedly, which was unnecessary.

(5) Low level of maintenance staffs

The maintenance staff in the hospital lacked systematic technical training; therefore, they had low maintenance level.

There are some measures.

(1) Sharing resources

Requirements on large medical equipment are limited in the same area in a certain period of time. Excessive configuration will cause resource waste. The department of health should design plans for allocating large medical equipment in a region and share resources. When the original equipment are left unused after some novel equipment were purchased, then administrative department for health can regulate those equipment to the places where need them.

(2) putting strict requirements on purchasing procedures

Procedure for examination and approval of purchasing large medical equipment should be strict. Responsibilities should be traced if equipment is excessively sold and used. Pursuing for high and new technology blindly or being keen on gaining petty advantages should be avoided. Products which have strong functions and will not be eliminated in a short time are advocated [17]. The flow of equipment purchasing is shown in Fig. 12.

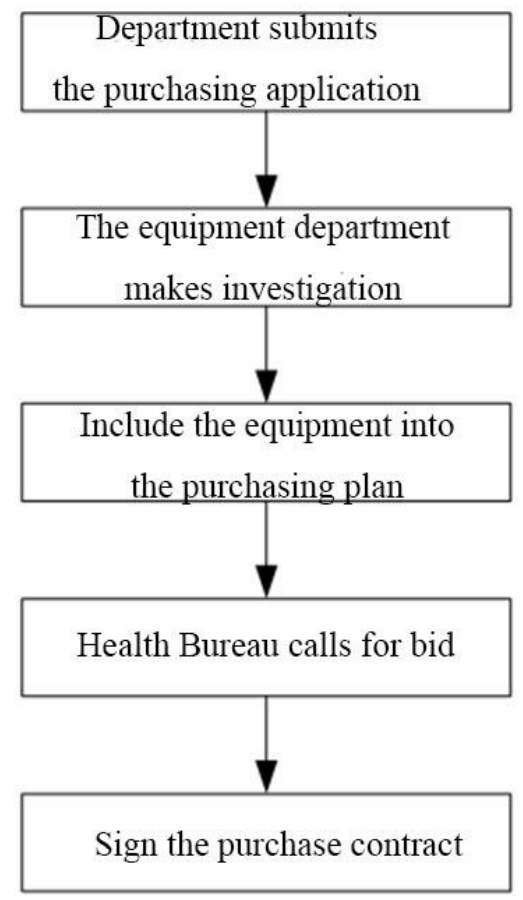

Fig. 12 The flow of equipment purchasing

(3) Improving management 
The management of medical equipment puts forward higher requirements for managers [18]. Hospitals should regularly train and evaluate equipment management staffs, strive to improve the management level of managers, and encourage office staffs to manage equipment and reduce equipment loss caused by human factors and give full play to the value of equipment through proper reward and punishment mechanism. The training method for management staff is shown in Fig. 13.

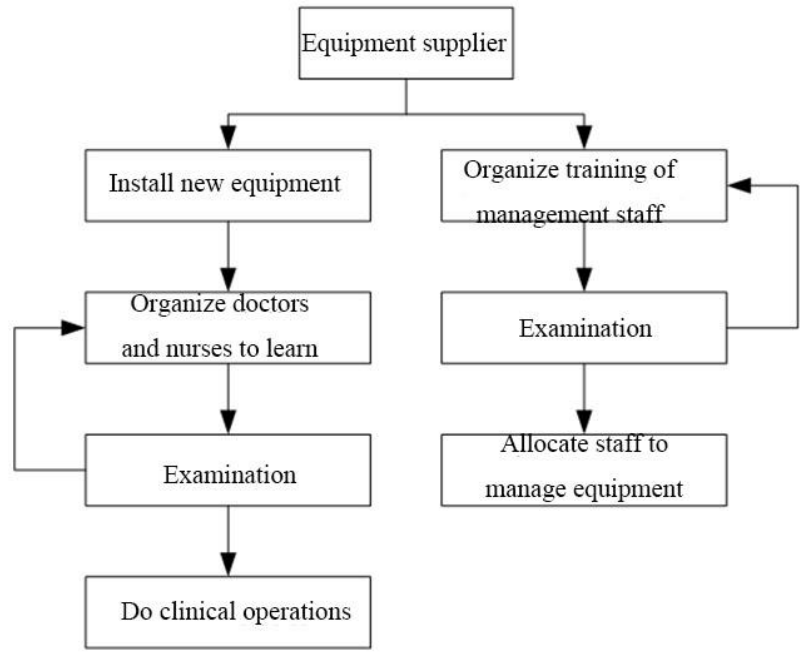

Fig. 13 The training method for management staff

(4) Improving the level of maintenance staff.

The maintenance personnel shall carry out preventive maintenance on the equipment according to the equipment manual [20], timely check small faults, and carry out separate maintenance for different equipment according to their fault prone environment. When the equipment fails, the process as shown in the figure below can be used.

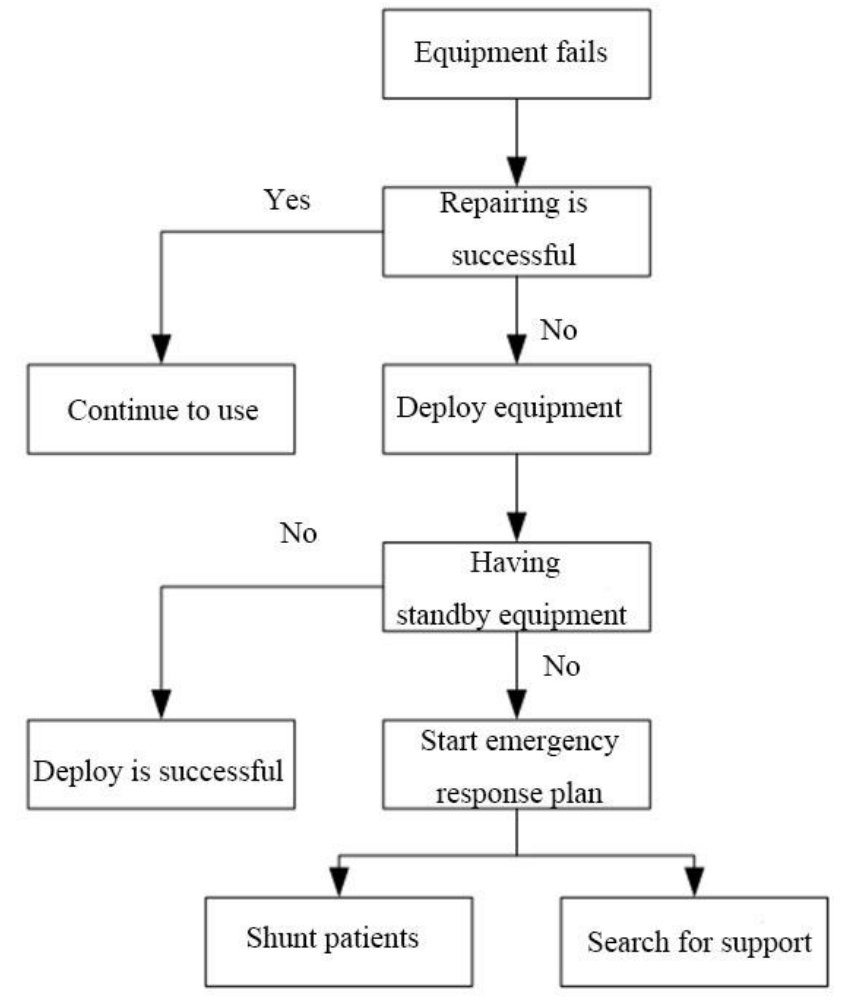

Fig. 14 Fault processing flow

(5) Making demand analysis

Before purchasing, it is necessary to analyze the number and usage of the existing equipment in the hospital. It is better to judge what equipment is most favorable for the hospital and patients under the guidance of experts and understand the needs and preferences of operators and patients.

(6) Saving equipment cost

The purchase cost of large-scale equipment is relatively high. When purchasing new equipment, the cost of procurement can be saved by means of medical competition bidding. In the process of using the equipment, different diagnosis and treatment steps may cause different cost consumption; therefore, it is necessary to compare and analyze them, select economic diagnosis and treatment steps, and optimize clinical diagnosis and treatment process to save costs.

(7) Establishing archives management system

The whole process of equipment information from purchase, use, maintenance to scrapping should be supervised and recorded. The file content includes instructions, acceptance reports, precautions, etc.

\section{CONCLUSION}

In this study, the economic benefits of some large medical equipment in a hospital in Suzhou, China, were analyzed. It was found that the number of B ultrasound machines in this hospital was the largest, and the number of other equipment was less than five. From the perspective of income and expenditure, CT and MRI machines had high income and expenditure, high 
frequency of use, and good economic benefits, while the power frequency X-ray machine was poor; the service efficiency of all the equipment was high. Then, on the above basis, the problems existing in the equipment management of the hospital were analyzed, and some suggestions were put forward. Data collection of large medical equipment was not sufficient, and there were also some deficiencies due to the limited conditions. For the scientific management of large medical equipment, further investigation and research are needed.

\section{REFERENCES}

[1] S. Taghipour, D. Banjevic, and A. K. S. Jardine, "Prioritization of medical equipment for maintenance decisions," J. Operat. Res. Soc., pp. 1666-1687, 2017.

[2] H. X. Wu, X. T. Zhang, and G. H. Wang, "Design of a Web-based Medical Equipment Management System for Clinical Engineering," Chin. J. Biomed. Eng., vol. 25, no. 03, pp. 11-17, 2016.

[3] E. K. Zhang, J. L. Gao, and S. S. Li, "Cost-benefit analysis of medical equipment in large equipment resource allocation," China Med. Equipment., vol. 9, no. 1, pp. 51-54, 2012.

[4] Y. P. Su, Q. H. Yun, and L. Cui, "Research on scientific management of medical equipment," China Med. Equipment., vol. 10, no. 9, pp. 78-80, 2013.

[5] Z. Zuo, and M. Ming, "Research on large medical equipment maintenance and repair," China Med. Equipment., vol. 11, no. 3, pp. 76-77, 2014.

[6] S. Cao, and L. S. Zhang, "The Cost of Large Medical Equipment Mathematical Model of Performance Appraisal," Progr. Biomed. Eng., no. 2, pp. 80-84, 2011.

[7] H. G. Jiang, C. J. Wang, and H. J Zhou, "Discussion and practice on the cost-benefit analysis of large-scale medical equipment," China Med. Equipment., vol. 10, no. 12, pp. 71-73, 2013.

[8] C. Y. Liu, M. Li, and M. L. Chen, "The Cost-Benefit analysis of large medical equipment," China Med. Equipment., vol. 12, no. 2, pp. 101-103, 2015.

[9] S. A. Jahad, M. Barouni, and M. R. Amiresmaeili, "Evaluation of economic efficiency in radiology wards: a case study in kerman province," Sadra Med. Sci. J., vol. 4, no. 1, pp. 31-41, 2016.

[10] A. Keshtkaran, "Evaluating the Economic Efficiency of Radiology Units in General Hospitals of Shiraz University of Medical Sciences in 2012, using Data Envelopment Analysis," J. Health. Dev., vol. 2, no. 4, pp. 340-352, 2014.

[11] C. Gao, L. Guo, F. Gao, and B. Yang, "Innovation design of medical equipment based on TRIZ," Technol. Health Care, vol. 23, no. s2, pp. S269-S276, 2015.

[12] J. Sun, H. Gu, Q. Wen, and H. Luo, "Assessing equity in the distribution of high-technology medical equipment in Guangxi: evidence from an ethnic minority region in Southern China," Int. J. Equity Health, vol. 16, no. $1,2017$.

[13] S. Q. Lin, and K. Cai, "The Analysis on allocation status and problem of the large medical equipment," China Med. Equipment, vol. 13, no. 7, pp. 121-123, 2016.

[14] C. Barbosa. J.W. Bray, W. N. Dowd, M. J. Mills, P. Moen, B. Wipfli, R. Olson, and E. L. Kelly, "Return on Investment of a Work-Family Intervention: Evidence From the Work, Family, and Health Network," $J$. Occup. Environ. Med., vol. 57, no. 9, pp. 943-51, 2015.

[15] T. Zis, P. Angeloudis, M. G. H. Bell, and H. N. Psaraftis, "Payback Period for Emissions Abatement Alternatives: Role of Regulation and Fuel Prices," Transp. Res. Record J. Transp. Res. Board, vol. 2549, no. 1, pp. 37-44, 2016.

[16] Z. H. Dong, P. B. Wang, and C.T. Sun, "Cost management and benefit analysis of medical devices," China Med. Equipment., vol. 13, no. 6, pp. 110-112, 2016.

[17] J. Wang, Q. H. Li, and H. J. Yu, "Evidence-based Research on Economic Benefit of Large-scale Medical Equipment for Hospital," Chin. Med. Equipment. J., vol. 33, no. 8, pp. 91-92, 2012.

[18] K. Ishida, M. Hirose, K. Fujiwara, H. Tsuruta, and N. Ikeda, "Analysis of Medical Equipment Management in Relation to the Mandatory Medical
Equipment Safety Manager (MESM) in Japan," J. Healthcare. Eng., vol. 5, no. 3, pp. 329-346, 2014.

[19] M. Masmoudi, Z. B. Houria, A. Al Hanbali, and F. Masmoudi, "Decision Support Procedure for Medical Equipment Maintenance Management," $J$. Clin. Eng., vol. 41, no. 1, pp. 19-29, 2016.

[20] N. Saleh, A. Sharawi, M. A. Elwahed, and A. Petti, "Preventive Maintenance Prioritization Index of Medical Equipment Using Quality Function Deployment," IEEE J. Biomed. Health Inform., vol. 19, no. 3, pp. 1029-1035, 2015.

Maojun Wang has received the master's degree. She is working in the First Affiliated Hospital of Soochow University, China. She is interested in hospital management and public affairs administration.

\section{Creative Commons Attribution License 4.0 (Attribution 4.0 International, CC BY 4.0)}

This article is published under the terms of the Creative Commons Attribution License 4.0 https://creativecommons.org/licenses/by/4.0/deed.en_US 